TAPROBANICA, ISSN 1800-427X. October, 2012. Vol. 04, No. 02: pp. 105-107, 1 pl.

(C) Taprobanica Private Limited, 146, Kendalanda, Homagama, Sri Lanka.

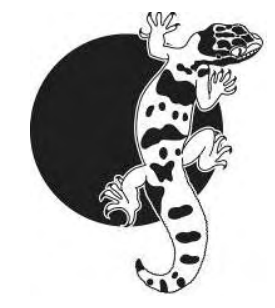

\section{Carapacial scute anomalies of star tortoise (Geochelone elegans) in Western India}

The basic taxonomy and classification of reptile species and genera often use pholidotic characters. Despite that each species has a standard pattern, there are always deviant individuals in terms of scale number, shape, size, or color. Turtles are excellent models for the study of developmental instability because anomalies are easily detected in the form of malformations, additions, or reductions in the number of scutes or scales (Velo-Antón et al., 2011). The normal number of carapacial scutes in turtles is five vertebrals, four pairs of costals, and 12 pairs of marginals, a pattern known as "typical chelonian carapacial scutation" (Deraniyagala, 1939). Any deviation of vertebral, costal, or marginal scute numbers or their pattern represents an anomaly. Zangerl \& Johnson (1957) documented scutation anomalies in 118 species of turtles belonging to seven families, with higher levels of carapace anomalies in aquatic species compared to semiaquatic and terrestrial species.

Here, I present some new information on scale anomaly observed in the Indian Star Tortoise (Geochelone elegans), especially in western populations. This species was first described by Schoepff (1795). It is widely distributed in dry, deciduous and scrub jungles of India, Sri Lanka and Pakistan. There are three disjunct distribution patches (Das, 1995, de Silva, 2003; Fife, 2007; Frazier, 1992). Geochelone elegans has a characteristic number of scales/scutes on the carapace, consisting of five symmetric vertebrals, four pairs of costals (pleurals), eleven pairs of marginals, and a single supracaudal. A nuchal scute is lacking. On the plastron there is a pair of gular, humeral, pectoral, abdominal, femoral, and anal scutes, along with paired axillary and inguinal scutes (Das, 1995; Frazier, 1987). De Silva (2003) provided drawings of carapace and plastron of the species showing the typical scale arrangement and the carapace drawings are from the sources of Deraniyagala (1939). But the 'Figure 5' (on page 13) shows something else, an illustration which is not a typical scale drawing of the species. This figure of a tortoise shows abnormal scales and scutes, especially vertebral, costal and marginal scutes, which are in higher numbers than the provided description of the species by Schoepff (1795).

\section{Observations (see plate 1 for figures)}

During the last eleven years (1990-2011), I have come across many star tortoises in the wild $(n=65)$ and in captivity $(n=135)$, belonging to different ages and sizes (from hatchlings to a 55 year old, which was the largest one) (Vyas, 2011). All specimens were bred under natural conditions (although 5 of the 6 specimens with anomalies were later kept in captivity). The details of anomaly of scales/scutes of each specimen are as follows.

Specimen 1 (S1): An approximately fourteenyear-old healthy female tortoise found in the wild (near Timba, Panchmahal District, India) with abnormal scutes. This female has typical scales and scutes on the plastron and carapace except for an extra costal scute on its left side and a triangular vertebral scute between the $3^{\text {rd }}$ and $4^{\text {th }}$ vertebrals (Fig. 1A). This extra costal scute developed on left side of the animal due to an extra vertebral scute.

Specimen 2 (S2): A female tortoise, having over nine growth rings on body scales. This animal had an extra pair of costal scutes and a vertebral scute on the carapace (Fig. 1B). The plastron scutes were normal and in typical shape. This animal was confiscated by the forest department from a local pet owner at Vadodara. Such abnormality of the costal and vertebral scutes might have possibly resulted from the splitting of one of the vertebral and costal scutes during the embryonic development.

Specimen 3 (S3): A six-year-old healthy tortoise found in captivity (Sayaji Baug Zoo, Vadodara) with abnormal scutes. This tortoise had typical 
scales and scutes on the plastron, but on the carapace it had an extra costal scute on its right side and a triangular vertebral scute of the $4^{\text {th }}$ vertebral (Fig. 1C). All right side costal scutes were larger than the left ones, due to this extra costal scute development on the carapace.

Specimen 4 (S4): A five-year-old specimen from captivity (private pet owner) having abnormal scutes on the carapace. This tortoise had typical scales and scutes on the plastron, but on the carapace, it had an extra pair of costal scutes and a large $1^{\text {st }}$ vertebral scute (Fig. 1D). The extra pair of costal scutes might be a development of improper split on the $1^{\text {st }}$ vertebral during its embryonic development.

Specimen 5 (S5): A juvenile captive tortoise having abnormal scutes on the carapace. This tortoise had normal plastron, but had an extra costal scute on its left side and an extra triangular vertebral scute between the $4^{\text {th }}$ and $5^{\text {th }}$ vertebrals (Fig. 1E). All left side costal scutes were narrower in comparison to the right costals.

Specimen 6 (S6): An over six-year-old healthy captive tortoise (retrieved from a pet animal trader) having normal and typical scutes, except on the carapace. The specimen had an extra pentagonal scute between the $4^{\text {th }}$ and $5^{\text {th }}$ vertebrals and an extra costal scute on its right side (Fig. 1F).

The scale/scute anomaly was observed in $3 \%$ of specimens. Anomalies were found only in the carapace, in the shape and size of vertebral and costals. These instances were recorded in a wide age span (fourteen- to four-year-old animals), suggesting that such anomalies have no negative effect to the health of animals.

The occurrence of anomalies, malformations or asymmetries in wild animals may serve as an indicator of developmental instability, a variable negatively correlated with fitness (Moller, 1997). Such type of anomaly phenomenon was earlier reported for star tortoises by de Silva (1995, 2003), Frazier (1987) and Fife (2007).

de Silva (1995, 2003) and Frazier (1987) stated that the numbers of scales and scutes are constant with hardly any distinct variation in the species. Fife (2007) mentioned that tortoise is occasionally seen with irregular scutes, either an extra scute or a split scute. This condition occurs in nature but is most commonly seen in captive hatched specimens.

Frazier (1987) stated after examining 98 specimens (most probably from the western population only) that "there was a tendency for an animal with an abnormal number of left costals to also have an abnormal of right costals. The same applies for marginals. Otherwise, there was no tendency for an animal with an abnormality in one kind of scale to also have an abnormality in another kind, abnormal vertebrals do not usually occur with together abnormal marginals". Here, what I have found does not follow the above statement. All six specimens have abnormal costals (either on the right side, the left side, or both) and vertebrals but these do not reflect abnormality with the marginal scales, except the seam contacts of the animals.

In general, such irregular scute abnormalities are caused by multiple genetic, biotic and abiotic factors. Three non-exclusive sources have been proposed as the main causes of scute or scale anomalies in reptiles: (i) temperature and moisture constraints during incubation (Lynn \& Ullrich, 1950), (ii) damaging effects of pollution (Bishop et al., 1994, 1998) and (iii) loss of genetic diversity in bottlenecked or inbred populations (Schwaner, 1990; Soule, 1979).

Fife (2007) stated that the abnormalities in the species are a result of higher temperatures during the incubation. Extreme incubation temperatures cause irregular scutes or other deformities. The study of Velo-Antón et al., (2011) suggested that genetic factors play an important role in the origin of anomalies in wild turtle populations and might serve as an indirect estimate of fitness in natural populations, but many factors clearly influence embryonic development and thus, disentangling what factors influence the occurrence of carapace scute anomalies in wild populations requires further studies using integrative approaches.

\section{Acknowledgements}

I am thankful to Superintendent of Surat Zoo and Curator of Sayaji Baug Zoo, Vadodara along with a number of private pet owners and pet traders from Gujarat State for allowing me to study and examine the tortoises from their 
collections. Thanks to Deputy Conservator Forest (wildlife) and Range Forest Officers, Forest Department, Vadodara, Gujarat State for allowing me to examine few confiscated specimens and support. Finally Richard Gemel (NMW - Austria) and Johanna Bleecker (McGill University - Canada) are acknowledged for reviewing the manuscript and valuable comments.

\section{Literature Cited}

Bishop C. A., G. P. Brown, R. J. Brooks, D. R. Lean and J. H. Carey, 1994. Organochlorine contaminant concentrations in eggs and their relationship to body size, and clutch characteristics of the female common snapping turtle (Chelydra serpentina serpentina) in lake Ontario, Canada. Archives of environmental contamination and toxicology, 27: 82-87.

Bishop, C. A., P. Ng, K. E. Pettit, S. W. Kennedy and J. J. Stegeman, 1998. Environmental contamination and developmental abnormalities in eggs and hatchlings of the common snapping turtle (Chelydra serpentina serpentina) from the Great Lakes-St. Lawrence River basin (1989-91). Environ Pollution, 101: 143-156.

Das, I., 1995. Turtles and Tortoises of India. World Wide Fund for Nature- India \& Oxford University Press, Bombay: 176.

Deraniyagala, P. E. P., 1939. The Tetrapoda reptiles of Ceylon Vol. 1. Testudinates and Crocodilians. Colombo Museum: 412.

de Silva, A., 1995. The status of Geochelone elegans in north western province of Sri Lanka: preliminary findings. Proceedings International Congress of Chelonian Conservation. Soptom, Gonfeeron: 47-49.

de Silva, A., 2003. The Biology and Status of the Star Tortoise (Geochelone elegans, Schoepff, 1795) in Sri Lanka. Protected Area Management and Wildlife Conservation Project, Ministry of Environment and Natural Resources, Sri Lanka: 100.

Fife, J. D., 2007. Star Tortoises: The Natural History, Captive Care, and Breeding of Geochelone elegans and Geochelone platynota. Living Art Publishing, USA: 116.
Frazier, J., 1978. Biology and conservation of Indian turtles and tortoises. Interim report to the American Institute for Indian studies, New Delhi: 64.

Frazier, J., 1992, Management of tropical chelonians: Dream or Nightmare? In: Tropical Ecosystems: Ecology and Management, Singh K. P. and J. S. Singh (eds.). Wiley Eastern Limited, New Delhi: 125-135.

Lynn, W. G. and M. C. Ullrich, 1950. Experimental production of shell abnormalities in turtles. Copeia, 1950: 253-263.

Moller, A. P., 1997. Developmental stability and fitness: A review. American Nature, 149: 916932.

Schoepff, J. D., 1795. Naturgeschichte der Schildkroten mit Abbildungen erlauter (17921801). Funfter Heft. Erlangen, Johann Jakob Palm: 89-136+17-25pls.

Schwaner, T. D., 1990. Geographic variation in scale and skeletal anomalies of tiger snakes (Elapidae, Notechis scutatus ater complex) in Southern Australia. Copeia, 1990: 1168-1173.

Soule, M. E., 1979. Heterozygosity and developmental stability: another look. Evolution, 33: 396-401.

Velo-Antón, G., C. G. Becker and A. CorderoRivera, 2011. Turtle Carapace Anomalies: The Roles of Genetic Diversity and Environment. PlosOne, 6 (4): 1-11.

Vyas, R., 2011. Record size of Indian Star Tortoise: Geochelone elegans (Schoepff, 1795). Russian Journal of Herpetology, 18 (1): 47-50.

Zangerl, R. and R. G. Johnson, 1957. The nature of shield abnormalities in the turtle shell. Fieldiana Geology, 10: 341-362.

Submitted: 26 March 2012, Accepted: 28 October 2012 Sectional Editor: Uwe Fritz

$$
\text { Raju Vyas }
$$

No. 505, Krishnadeep Tower, Mission Road, Fatehgunj, Vadodara, Gujarat, India. E-mail: razoovyas@hotmail.com 


\section{PLATE 01}
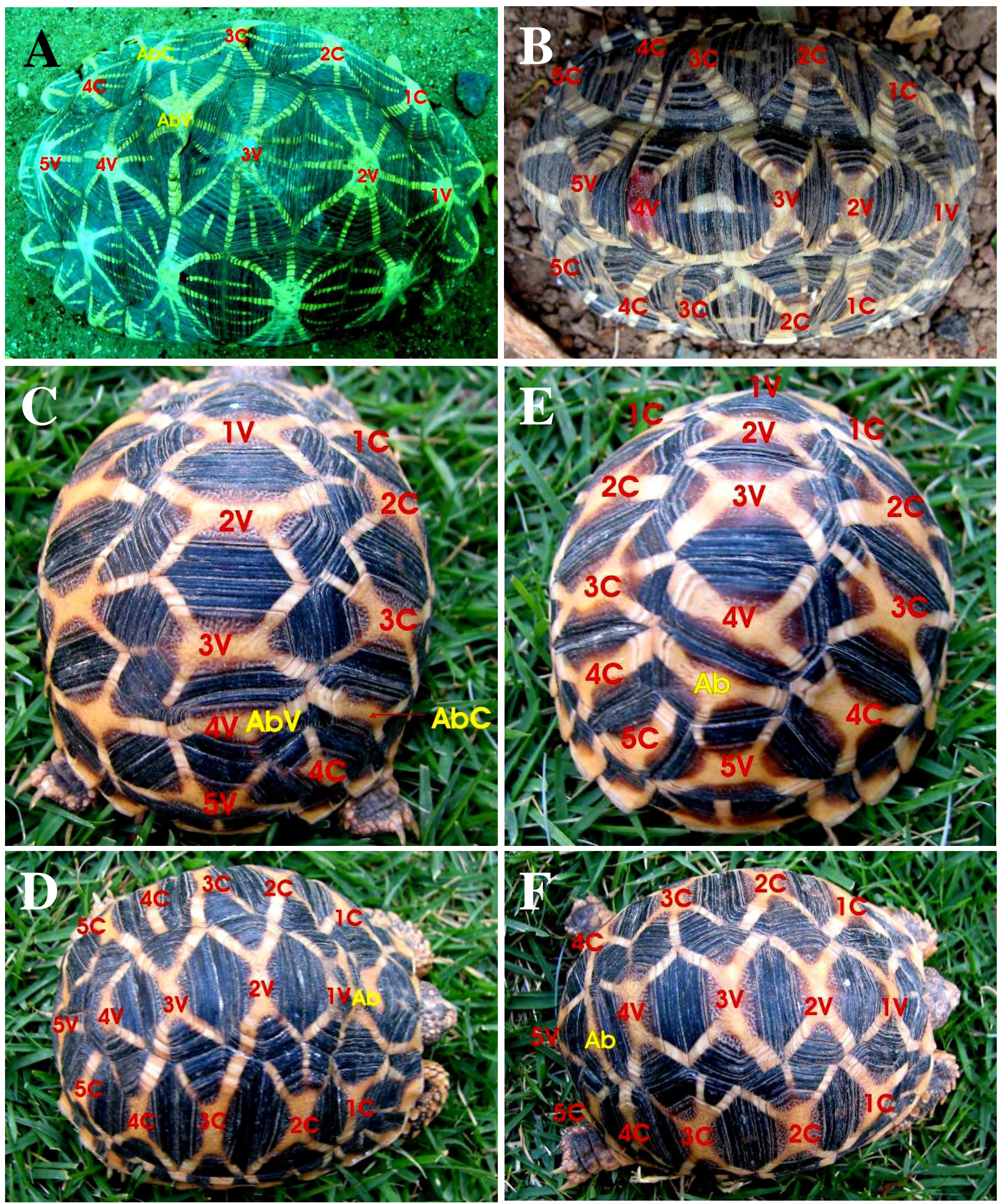

Figure 1: Geochelone elegans, A: extra triangular vertebral and costal (S1); B: extra vertebral and a pair of costal (S2); C: extra vertebral and an extra left costal (S3); D: extra pair of costal and large $1^{\text {st }}$ vertebral scute (S4); E: extra costal on the left and an extra triangular vertebral scute between $4^{\text {th }}$ and $5^{\text {th }}$ vertebrals (S5); F: extra pentagon shaped vertebral and an extra costal on its right (S6). 